\title{
Study of Influence of Vaginal Ph on the efficacy of Dinoprostone gel for Induction of Labor
}

\author{
J Sowmya ${ }^{\circledR 1}$, T Vijaya Krishna ${ }^{\circledR 2}$ \\ ${ }^{1}$ Senior Resident, Department of Obstetrics and Gynecology, MGM Hospital, Warangal, Telangana, India, ${ }^{2}$ Associate Professor, Department of Obstetrics and \\ Gynecology, Niloufer Hospital, Osmania Medical College, Hyderabad, Telangana, India.
}

\section{Abstract}

Background: Inducing labor is a procedure intended to trigger artificial contractions of the uterus that generally involve progressive erasure and dilation of the cervix. This will hopefully lead to the birth of a baby through the vaginal route. To assess the efficacy of dinoprostone gel in cervical maturation and its effect on vaginal $\mathrm{pH}$. Subjects and Methods: The participants were grouped by their vaginal $\mathrm{pH}$ into two groups. Group, I included patients with vaginal $\mathrm{pH} \leq 4.5$ and Group II included vaginal $\mathrm{pH}>4.5$ and the differences between the groups with respect to maternal age, parity, gestational age. Those women with minimal change in Bishop Score, received up to 3 doses of dinoprostone gel intracervically, 6 hours apart. Women, who had no change in Bishop Score at the end of induction with 3 doses of dinoprostone, were further reassessed. Results: There was no statistically pertinent relationship between the two groups in regard to maternal age, gestational age, parity, and initial Bishop Score. The mean maternal age in Group I was 25.9 years and Group II was 26.9 years. The mean gestational age was 39.5 weeks in group I and 38.9 weeks in group II. The majority of subjects were primigravidas ( 70 percent in group I and 63 percent in group II). The mean Bishop score before labor induction was 3.6 \pm 0.9 in Group I and $4 \pm 1.0$ in Group II. Out of 200 cases, 33 (23.3 percent) needed an improvement in Oxytocin, 33 (33.3 percent) in Group I and 4 (13.3 percent) in Group II. The vaginal delivery rate was 90\% in Group I and 87\% in Group II. The Caesarean section was marginally higher in Group II (10 percent) compared with Group I (13 percent). Conclusion: Parity has a major impact on the pre-induction of the Bishop Score and the $\mathrm{pH}$ itself has a vaginal influence. Knowing the pre-induction vaginal $\mathrm{pH}$ may also be a helpful method for determining the outcome of PGE2 induction.

Keywords: Vaginal Ph, Labor, Induction, Dinoprostone, PGE2 Gel

Corresponding Author: T Vijaya Krishna, Associate Professor, Department of Obstetrics and Gynecology, Niloufer Hospital, Osmania Medical College, Hyderabad, Telangana, India.

E-mail: drtvijayakrishna@gmail.com

Received: 01 November 2020

Revised: 18 December 2020

Accepted: 26 December 2020

Published: 30 December 2020

\section{Introduction}

Labor induction is used to induce cervical maturation and facilitate cervical maturation. Contraction of the uterus. Approximately $20-30 \%$ of all pregnancies need Induction of labour. ${ }^{[1]}$ Post-term birth, membrane-free breakage, gestational hypertension, oligohydramnios, unsettling fetal complications and numerous maternal diseases such as chronic hypertension and diabetes are more popular indications. Induction of labour is now one of the world's most effective interventions. Up to $20 \%$ of women worldwide had labour in one way or another. The rates of induction differ from experience to cultural context. The presence of better and more predictable modern oxytocic and induction approaches than previous procedures has made the induction mechanism more smooth. ${ }^{[2]}$ The most used pharmacological strategies of encouraging cervical ripening and labor inductivity are intravaginal or intracervical administration of PGE2 (dinoprostone) and intravaginal administration of exogenous PGE1 (misoprostol) ${ }^{[3]}$ One of the considerations that determine the potency of PGE2 is vaginal $\mathrm{pH} .{ }^{[4]} \mathrm{pH}$ ranges from 4-4.5 the amount of vaginal transudate is affected by the involvement of cervical mucosa. The acid produced by lactobacillus glycogen plays an important role in the preservation of the acidic $\mathrm{pH}$ environment in the vagina. ${ }^{[5]}$ Many factors may alter normal vaginal $\mathrm{pH}$, including inflammation of the lower genital tract, bacterial vaginosis, membrane rupture, douching, etc. Prostaglandins are organic acids with reduced $\mathrm{pH}$ solution solubility. The acidity from the vagina will also affect drug release, resulting in unpredictable clinical outcomes. While a wide range of literature on the effectiveness of prostaglandins for induction has been accessible, relatively few studies have shown variables that impact the overall effec- 
tiveness of prostaglandins for induction of labor. The goal of this research is to establish the vaginal $\mathrm{pH}$ effect on the efficacy of Dinoprostone (PGE2) gel in cervical maturation in patients with an unfavorable cervix, which will contribute to the patient selection of PGE2 labour triggers and reduce the frequency of induction failure.

\section{Subjects and Methods}

Study Design: A prospective observational study

Place of Study: Niloufer Hospital, Osmania Medical College, Hyderabad, India.

Duration: October 2018 to October 2019

Study population : Both pregnant women aged 18-35 who had been admitted into safe confinement in the Department of Obstetrics and Gynecology and were between 37 and 42 weeks of gestation were enrolled. All participants had a diagnostic or obstetric indication for labour induction.

Sample Size: 200 women divided equally into 2 groups.

\section{Inclusion Criteria}

- Score of unfavorable cervical bishop $\leq 5$,

- No contraindication for delivery by the vagina route;

- NST reactive,

- Lack of involuntary uterine contraction.

- Singleton pregnancy with the presentation of the vertex

\section{Exclusion Criteria}

- Documented hypersensitivity to prostaglandins, Placenta previa, Chorioamnionitis presumed,

- Cephalopelvic disproportion, ruptured membranes, clinically apparent genital infection

- Parity of $>3$;

- Prior effort to induce labor for this pregnancy;

- Prior cesarean delivery or history of uterine surgery;

\section{Methods}

- All compliant patients gave written and informed consent.

- Before the planned induction of labor, all applicants were enrolled and cardiotocographic tests were conducted to eliminate fetal distress and uterine contractions.

- A speculum analysis was performed on each participant; and the $\mathrm{pH}$-value of the vaginal was measured using a wide and narrow $\mathrm{pH}$ paper. The indicator paper has been placed between the valves of the Cusco speculum on the lateral vaginal wall until it becomes wet. The strip color variations were instantly compared to the colorimetric scale of the manufacturer and the results were documented.
- The participants were classified into two subgroups as Group I and Group II depending on their vaginal $\mathrm{pH}$. Group, I comprised patients with vaginal $\mathrm{pH} \leq 4.5$ and Group II included vaginal $\mathrm{pH}>4.5$ and discrepancies within groups with regard to menstrual age, parity, gestational age. [6]

- After pH measurement, the Bishop score was calculated on the basis of the following parameters: cervical dilation, cervical position, cervical consistency, fetal station. A score of $0-2$ or $0-3$ was given to each part. The highest possible score was 13 and $<5$ is unfavorable and induction is necessary. [7]

- Induced all women to the initial dose of intracervical placed dinoprostone gel $(0.5 \mathrm{mg})$. The patient was advised to stay reclusive for a period of 30 minutes after application.

- A repeat score of the Bishop was assigned after the initial 6 hours of cervical instillation.

- All participants were exposed to the uniform intrapartum care regimen.

- Those women with minimal change in Bishop Score, received up to 3 doses of dinoprostone gel intracervical, 6 hours apart.

- Women, who had no change in Bishop Score at the end of induction with 3 doses of dinoprostone, were further reassessed.

- Women who had any improvement in Bishop Score but are not in sufficient labor got Oxytocin infusion for improvement.

- The shift in Bishop's score over 6 hours, inductionactive step interval, induction-interval of delivery, mode of delivery and the neonatal outcome is recorded for both categories.

Ethical Clearance: Ethical clearance was obtained from the institute's ethical committee prior to the commencement of the study.

Statistical Analysis: SPSS 24.0 software was used for statistical analysis. $\mathrm{P}<0.05$ was considered statistically significant.

\section{Results}

A total of 200 women with an unfavorable cervix were enrolled in this prospective study. In group I, there were 100 cases with a vaginal $\mathrm{pH}$ of $\leq 4.5$ and in group II, 100 cases with vaginal $\mathrm{pH}$ of $>4.5$. In relation to mother's age, parity, gestation, Bishop's induction score, repeat induction need, inductionactive interval process, induction-delivery interval, delivery mode and Neonatal outcomes, vaginal $\mathrm{pH}$ was calculated. The mean age in Group I was 25.9 years and Group II was 26.9 years. The range was between 18 and 35 years old. The majority of patients was 37-41 weeks of gestational age and was equally distributed in all categories with a p-value of 
0.09 . The mean gestational age was 39.5 weeks in group I and 38.9 weeks in group II. There was no statistically meaningful correlation between the two classes with regard to maternal age, gestational age, parity and the original Bishop scores.

The mean Bishop score before labor induction was 3.6 \pm 0.9 in Group I and $4 \pm 1.0$ in Group II. The majority of subjects (60 percent in Group I and 37 percent in Group II) had a preinduction Bishop score of 4.

No substantial association has been identified between vaginal $\mathrm{pH}$ and maternal age. Subjects with a higher vaginal $\mathrm{pH}$ $(>4.5)$ required a higher number of inductions compared to subjects with lower vaginal $\mathrm{pH}$, but this observation was not statistically significant. The majority of subjects in both groups required only one dose of PGE2 to initiate labor.

$\mathrm{p}$ value $=0.28$, not significant $(\mathrm{p}<0.05$ is significant $)$

Data analysis found that the number of vaginal deliveries was comparable in categories, 90 percent in group I and 87 percent in group II with a p-value of 0.28 . The Caesarean section incidence was comparable in both categories (10 percent vs 13 percent) with a p-value of 0.28 as seen in the table above.

There was no substantial variation between groups in the mode of delivery.

In Group II, Bishop's score changes over 6 hours after the start of the first intracervical dinoprostone gel were significantly higher than those in Group I ( 23 versus 10, p-value 0.15 ). No substantial relationship has been identified between vaginal $\mathrm{pH}$ and induction-active step interval, induction-delivery interval. Out of 200 cases, 14 (23.3 percent) required a rise in Oxytocin, 33 (33.3 percent) in Group I and 13 (13 percent) in Group II.

Analysis of neonatal outcome showed that average birth weight, APGAR score at 5 minutes, need for NICU admission were similar in both the groups. Total 17 babies required NICU care, of which 7 were from the group I and 10 from group II. The most common indication for NICU admission was respiratory morbidity in both groups. All babies were discharged within a week. No perinatal morbidity in both groups.

\section{Discussion}

This prospective retrospective research was conducted at the Department of Obstetrics and Gynecology, Niloufer Hospital, Osmania Medical College, Hyderabad, India. A total of 200 term pregnant women have been included in the report. Vaginal $\mathrm{pH}$ value was measured prior to induction using both broad and narrow range $\mathrm{pH}$ documents. The participants were split into two categories as Group I (vaginal $\mathrm{pH} \leq 4.5)$ \& Group II (vaginal $\mathrm{pH}>4.5$ ) based on their vaginal $\mathrm{pH}$. The Bishop score was measured after
$\mathrm{pH}$ assessment. All women with unfavorable cervix were instilled by intracervical administration of the initial dose of dinoprostone gel $(0.5 \mathrm{mg})$. After the initial 6 hours of cervical maturation, a repeat score was assigned to the Bishop. The woman with marginal improvement in Bishop Score got up to 3 doses of dinoprostone gel intracervical, 6 hours apart. A standardized intrapartum treatment protocol has been used for all subjects. In this study, the mean maternal age was $25.9 \pm 4.4$ years in Group I and $26.9 \pm 4.5$ years in Group II. There has been no important correlation between vaginal $\mathrm{pH}$ and maternal age (p-value 0.39). This result was similar to the Goswami et al study $(24.4 \pm 3.47$ years in Group I and $23.13 \pm 3.95$ years in Group II) and the Onen et al study $(22.7 \pm 4.3$ years in Group I and $23.0 \pm 3.7$ years in Group II). The mean gestational age in our study was $39.5 \pm 0.9$ weeks in Group I and 38.9 \pm 1.3 weeks in Group II. There has been no substantial correlation between the vaginal $\mathrm{pH}$ and the gestational age of the participants. This was like Goswami et al, ${ }^{[8]}$ and Onen et al, ${ }^{[9]}$ studies. The majority of participants in this sample are primigravida (70 percent in group I and 63.33 percent in group II). No substantial correlation has been identified between the vaginal $\mathrm{pH}$ and the parity of subjects (p-value 0.584). The literature has also shown similar results. Kurian et al, ${ }^{[10]}$ however, demonstrated a strong correlation between vaginal $\mathrm{pH}$ and parity. Subjects with greater parity had a higher vaginal $\mathrm{pH}(\geq 5)$ that was statistically important. In the present analysis, the average Bishop score before induction was 3.6 \pm 0.9 in Group I and $4 \pm 1.0$ in Group II. Our analysis found no substantial connection between the vaginal $\mathrm{pH}$ and the pre-induction score of the Bishop. This result was like the analysis of Onen et al. However, Goswami et al and Kurian et al showed a marginally important correlation between vaginal $\mathrm{pH}$ and pre-induction of the Bishop score. Subjects with higher vaginal $\mathrm{pH}$ had higher Bishop Score scores prior to labor induction. In our research, subjects with higher vaginal $\mathrm{pH}(>4.5)$ needed better induction rates relative to subjects with lower vaginal $\mathrm{pH}$, but this finding was not statistically important. The majority of participants in both groups needed only one dose of PGE2 to start work (53.33 percent in group I and 60 percent in group II). However, in the Kurian et al report, subjects with higher vaginal $\mathrm{pH}(\geq 5)$ responded to a single induction, whereas subjects with lower vaginal $\mathrm{pH}$ needed a repeat induction (maximum of three doses at 6-hour intervals) that was statistically important. Labor results were identical in both classes in the present study. There was no statistically meaningful correlation between vaginal $\mathrm{pH}$ and bishop transition over 6 hours, induction-active step interval, induction-delivery interval, mode of delivery, neonatal outcome.

\section{Bishop Score Change Over 6 Hours}

In our study, Bishop's score changes over 6 hours after the start of the first intracervical dinoprostone gel were marginally 
Table 1: Baseline Characteristics

\begin{tabular}{llll}
\hline Characteristics & Group - I (mean \pm SD) & Group - II (mean \pm SD) & p-value \\
Maternal age (in years) & $25.9 \pm 4.4$ & $26.9 \pm 4.5$ & 0.39 \\
Gestational age (in weeks) & $39.5 \pm 0.9$ & $38.9 \pm 1.3$ & 0.09 \\
Vaginal pH & $4.1 \pm 0.3$ & $5.1 \pm 0.2$ & $<0.001$ \\
Initial Bishop score & $3.6 \pm 0.9$ & $4 \pm 1.0$ & 0.12 \\
\hline
\end{tabular}

Table 2: Comparison of Vaginal Ph with Maternal Age, Parity Comparison of Vaginal Ph and No. Of Times Subjects Were Induced With PGE2 and Comparison of Vaginal $P h$ and Induction-Active Phase Interval

\begin{tabular}{|c|c|c|}
\hline Maternal Age & Group - I & Group - II \\
\hline$\leq 25$ years $(\mathrm{n}, \%)$ & $50(50 \%)$ & $46(46 \%)$ \\
\hline$>25$ years $(n, \%)$ & $50(50 \%)$ & $54(54 \%)$ \\
\hline Primi & $70(70 \%)$ & $63(63 \%)$ \\
\hline Multi & $30(30 \%)$ & $37(37 \%)$ \\
\hline One & $53(53 \%)$ & $70(70 \%)$ \\
\hline Two & $27(27 \%)$ & $23(23 \%)$ \\
\hline Three & $20(20 \%)$ & $7(7 \%)$ \\
\hline \multicolumn{3}{|c|}{ Induction-Active phase interval } \\
\hline$\leq 6$ hours & $40(40 \%)$ & $60(60 \%)$ \\
\hline
\end{tabular}

Table 3: Comparison of Vaginal pH and Delivery Outcome

\begin{tabular}{lll}
\hline Mode of delivery & Group - I & Group - II \\
Vaginal delivery & $90(90 \%)$ & $87(87 \%)$ \\
LSCS & $10(10 \%)$ & $13(13 \%)$ \\
\hline
\end{tabular}

Table 4: Comparison of labor outcomes

\begin{tabular}{|c|c|c|c|}
\hline Outcome & \multirow{2}{*}{$\begin{array}{l}\text { Group - I } \\
10(1.9)\end{array}$} & \multirow{2}{*}{$\begin{array}{l}\text { Group - II } \\
23(2.9)\end{array}$} & \multirow{2}{*}{$\begin{array}{l}\text { P-value } \\
0.15\end{array}$} \\
\hline $\begin{array}{l}\text { Bishop score changes over } 6 \text { hours } \\
\text { (Median Q1, Q3) *** }\end{array}$ & & & \\
\hline Augmentation required $(\%) * *$ & $33.3 \%$ & $13.3 \%$ & - \\
\hline $\begin{array}{l}\text { Induction- Active phase interval in hours } \\
\text { (Median Q1, Q3) *** }\end{array}$ & $16(7.30)$ & $9(5.27)$ & 0.12 \\
\hline $\begin{array}{l}\text { Induction delivery interval in hours } \\
\text { (Median Q1, Q3) * }\end{array}$ & $19(9.35)$ & $11(7.29)$ & 0.14 \\
\hline \multicolumn{4}{|l|}{$\begin{array}{l}\text {-* student's t-test, } \\
\text {-** chi-square test } \\
\text { - *** Mann Whitney Test }\end{array}$} \\
\hline \multicolumn{4}{|l|}{ Table 5: Neonatal Outcome } \\
\hline Birth weight (in kgs) & $3.09 \pm 0.4$ & $3.03 \pm 0.3$ & 0.53 \\
\hline 5 min APGAR score $<7$ & 0 & 0 & - \\
\hline NICU admission (n \%) & $7(7)$ & $10(10)$ & - \\
\hline
\end{tabular}


higher in Group II compared to Group I (23 versus 10) This result was comparable to the Onen et al study, which concluded that the Bishop's score changes over 6 hours after the start of the first vaginal dinoprostone insert were substantially higher in the high vaginal $\mathrm{pH}$ group. Goswami et al showed similar results, the improvement in Bishop Score over 6 hours was 2.57 in Group I and 5.71 in Group II.

\section{Induction to Active Phase Interval}

In our analysis, the induction-active step interval was significantly higher in Group I compared with Group II (16 hours in group I and 8 hours in group II). The relationship was not statistically important. Our findings were similar to the Onen et al study, in which the period for active labor was $14.7 \pm 17.3$ in Group I and 13.1 \pm 9.8 in Group II. In comparison, Goswami et al demonstrated a strong correlation between vaginal $\mathrm{pH}$ and induction-active step period (21.45 \pm 8.81 hours in Group I and $11.99 \pm 7.65$ hours in Group II).

\section{Induction to Delivery Interval}

In this study, the delivery interval induction was significantly higher in group I (19 hours) relative to group II (11 hours). The relationship was not statistically important. Our findings were close to those of Onen et al, in which the inductiondelivery time was $20.0 \pm 21.4$ hours in Group I and 17.6 \pm 12.0 hours in Group II. In comparison, Goswami et al showed a strong correlation between vaginal $\mathrm{pH}$ and induction delivery interval (28.48 \pm 7.92 hours in Group I and $16.67 \pm 9.350$ hours in Group II).

\section{Need for Augmentation of Labor}

Out of 200 cases, 46 required augmentations either with Oxytocin, 33 belonged to group I and 13 to group II. Augmentation of labor requirement was slightly higher in group I $(33.3 \%$ versus $13.3 \%)$. This contrasts with the Goswami et al study in which augmentation was required in $7 \%$ of subjects in group I and $41 \%$ of subjects in group II.

\section{Mode of Delivery}

The vaginal delivery rate for our study was $90 \%$ in Group I and $87 \%$ in Group II. The cesarean section was significantly higher in Group II (13\%) than in Group I (10 percent). Goswami et al. reported $20 \%$ in Group I and $72 \%$ in Group II with vaginal delivery. The Caesarean section level for Group I was 80 percent and Group II was 28 percent. 60.5 percent of those given vaginally in groups I and 76 percent administered in groups II in a study conducted by Onen et al. In Group I, the rate for the Cesarean section was 39.5 percent and in Group II, 24 percent. Basirat et al found that the incidence of cesarean section was lower in women with elevated vaginal $\mathrm{pH}$. In contrast, our study found a higher prevalence of cesarean section in people with higher vaginal $\mathrm{pH}$.

\section{Comparison of Neonatal outcome}

Neonatal outcomes like mean birth weight, APGAR score at 5 minutes, need for NICU admission were comparable in both the groups like other studies. Neither our study nor other studies had neonatal deaths.

\section{Conclusion}

Our research showed that vaginal $\mathrm{pH}$ doesn't seem to have a significant impact on the effectiveness of dinoprostone gel in cervical maturation and labor induction. However, our research's observational evidence indicates that vaginal $\mathrm{pH}$ is unlikely to impact the effectiveness of dinoprostone gel.

\section{References}

1. Kudagi BL, Sailajai L, Kumari RP, Babu CR. A Comparative study of intracervical misoprostol with intracervical dinoprostone gel for induction of labor in pregnancy. Asian J Pharm Clin Res. 2013;6(2):174-178.

2. Ramsey PS, Ogburn PL, Harris DY, Heise RH, Ramin KD. Effect of vaginal $\mathrm{pH}$ on efficacy of the dinoprostone gel for cervical ripening/labor induction. Am J Obstet Gynecol. 2002;187(4):843-846. Available from: https://dx.doi.org/10. 1067/mob.2002.126987.

3. Das SCA, Kar M. A Review on Novelty and Potentiality of Vaginal Drug Delivery. Int J Pharmtech Res. 2011;3(2):10331077.

4. Basirat Z, Barat SH, Ghanbarpour A, Golsorkhtabaramiri M. Does vaginal $\mathrm{pH}$ affect the efficacy of dinoprostone in cervical ripening/labor duration? Clin Exp Obstetric Gynecol. 2012;39(4):522-527.

5. Sanchez-Ramos L, Gaudier FL, Kaunitz AM. Cervical Ripening and Labor Induction After Previous Cesarean Delivery. Clin Obstet Gynecol. 2000;43(3):513-523. Available from: https://dx.doi.org/10.1097/00003081-200009000-00011.

6. Hofmeyr GJ, Gulmezoglu AM. Vaginal misoprostol for cervical ripening and induction of labour. Cochrane Database Syst Rev. 2002;2:941-941. Available from: https://doi.org/10. 1002/14651858.cd000941.

7. Sanchez-Ramos L, Kaunitz AM. Misoprostol for Cervical Ripening and Labor Induction: A Systematic Review of the Literature. Clin Obstet Gynecol. 2000;43(3):475-488. Available from: https://dx.doi.org/10.1097/00003081-20000900000008 .

8. Goswami J, Choudhury SS, Deka G. Effect of vaginal pH in cervical ripening with dinoprostone gel. New Indian j OBGYN. 2015;2(1):32-36.

9. Fi O, Ozakflit G, Yilmaz B. The Role of Vaginal pH on Efficacy of Controlled-Release Dinoprostone Vaginal Insert for Cervical Ripening/Labor Induction: A Prospective Double-Blind Study . Turkish-German Gynecology Assoc. 2008;9:206-217.

10. Kurian M, Rao B, Rao A, A S. Effect of vaginal pH on efficacy of dinoprostone gel for labour induction. Int J Reprod Contracept Obstet Gynecol. 2016;5(4):1196-1201. Available from: https://dx.doi.org/10.18203/2320-1770.ijrcog20160884. 
Copyright: (C) the author(s), 2020. It is an open-access article distributed under the terms of the Creative Commons Attribution License (CC BY 4.0), which permits authors to retain ownership of the copyright for their content, and allow anyone to download, reuse, reprint, modify, distribute and/or copy the content as long as the original authors and source are cited.

How to cite this article: Sowmya J, Krishna TV. Study of Influence of Vaginal Ph on the efficacy of Dinoprostone gel for Induction of Labor. Asian J. Med. Res. 2020;9(4):5-10.

DOI: dx.doi.org/10.47009/ajmr.2020.9.4.OG2

Source of Support: Nil, Conflict of Interest: None declared. 